\title{
Venture Capital Investments for Life Sciences Start-ups in Switzerland
}

\author{
Pascal Gantenbein* and Nils Herold
}

\begin{abstract}
Despite its economic and technological importance, the Swiss life sciences sector faces severe challenges in attracting enough venture capital for its own development. Although biotechnology and medical technology have been the most important areas of venture financing from 1999 through 2012 according to our own data, average investment volumes nevertheless remain on a low level of only 0.05 percent of Swiss GDP. After 2008, there was a pronounced shift away from early-stage financing. While business angels still play an important role at the early stage, venture capitalists are the most important investor type by volumes having their main focus on expansion financing. The industry faces predominant challenges in securing capital availability for entrepreneurs, in transforming the highly skewed and back-loaded payoff profile of investments into a more stable return stream, and in defining appropriate business and collaboration models.
\end{abstract}

Keywords: Biotechnology · Business angels · Life sciences · Medical technology · Venture capital

\section{Introduction}

The economic contribution of the life sciences sector in Switzerland is remarkable. On the one hand, approximately 20,000 people generating a sales volume of roughly CHF 10 billion per year work in biotechnology and medical technology. Including suppliers and distributors even yields substantially higher numbers. On the other hand, this sector features an extraordinary density of experts contributing to a high level of innovation, which is again a prerequisite for future growth in Switzerland, as the development of the pharmaceutical industry clearly documents.

In spite of this, the financing of life sciences start-ups is a difficult task as ever both for investors and entrepreneurs. This is especially true in the case of venture capital, which term is subsequently used for equity investments in the early stage and the expansion stage of the company life cycle of high-technology start-ups. Venture capital investments in life sciences start-up companies in Switzerland have experienced massive swings over the past two decades. While in the United

\footnotetext{
$\overline{{ }^{*} \text { Correspondence: }}$ Prof. Dr. P. Gantenbein University of Basel

Faculty of Business and Economics

Peter Merian-Weg 6

$\mathrm{CH}-4002$ Basel

Tel.: +41612672459

E-mail: pascal.gantenbein@unibas.ch
}

States the early years of the modern life sciences industry and respective venture capital financing transactions date back to the 1970s, the development in Switzerland has substantially been lagging behind. Even in the 1990s, venture capital investments in life sciences only played a minor role in Switzerland, also within the class of start-up companies.

However, this has considerably changed: Over the past 15 years, life sciences have turned to represent the by far most important topic in the area of venture capital investments in Swiss high-technology firms. Our data from the Swiss Venture Capital Database at the University of Basel show that over the period from 1999 to 2012, $57 \%$ of the CHF 6.5 billion aggregate venture capital investment volume in Swiss high-tech start-ups went into life sciences. At the same time, both the proportion and the absolute investment volumes are far from being persistent on a constant level, which poses obvious challenges to the industry.

Against this background, three questions are of particular interest: First, which are the typical investment patterns and characteristics related to start-ups in general and, notably, to those in the life sciences industry observable over time? Second, what are the key drivers behind this development? And finally, how should the industry respond to the challenges and which strategies should companies in life sciences adopt in order to be competitive? Given the enormous importance of this sector for a country's long-term technology leadership and future economic growth, the answers to these questions must be relevant far beyond the borderline of companies and investors in this field.

\section{Dynamics of Venture Capital Investments in Life Sciences}

To better understand the dynamics of financing transactions in the area of life sciences, we first analyze the pattern of investments based on the data gathered in the Swiss Venture Capital Database. Hereby, the focus is on a) life sciences financing compared to venture capital investments in other industries, b) the development of average transaction volume over time, and, c) the relationship between biotechnology and medical technology.

Before the millennium, investments into biotechnology and medical technology remained on a low level both in relative and absolute terms. Up to year 2000, the transaction volume in Swiss high-tech start-ups was dominated by the sectors information and communication technology (ICT) and engineering. From that time on, this has changed significantly. While life sciences accounted for only $17 \%$ of total investment volume in 1999, the ratio has grown to $84 \%$ in 2004 and after a slight dip in 2005 back up to even $87 \%$ in 2009. Since then, however, the recorded financing volume has decreased to $51 \%$ in 2012.

During the same period, the average transaction volume in life sciences venture capital financing has massively dropped. In 2007, the average investment amount reached CHF 13.2 million, while the same number almost halved to CHF 6.8 million in 2011. This shift was primarily driven by the biotech sector. With CHF 11.9 million, the latter also exhibits considerably higher average transaction volumes as opposed to the CHF 5.7 million in the medical technology sector. Still, the average investment volumes are by far the highest in life sci- 
investment volume conducted by venture capitalists during the observation period went into early-stage financing. However, this proportion is not constant over time. Rather, it seems that venture capitalists have been more active as early-stage investors some years back, while lately shifting their focus on more mature businesses. This is sometimes associated with a higher degree of risk awareness, driven by the experience that due to high valuations in the entire pharma sector after the millennium, investment returns particularly in the biotech industry have been rather disappointing in many cases.

Nonetheless, to some extent, this pattern also results as a matter of course given that in the early years of an industry, there is also a natural prevalence of early-stage investments. Furthermore, early-stage financing calls for follow-up investments in the successful cases. Not only are the associated lot sizes larger, but quite often, there are also respective capital commitments. Interestingly, much of this shift towards expansion financing has appeared in the wake of the financial crisis of 2008. During these more challenging years, the necessary postponement of planned exits inevitably led to less capital available for new investments.

Overall, it has to be noted that venture capitalists play a crucial role for the development of start-ups in life sciences. Apart from the fact that half of the financing amount provided by venture capitalists between 1999 and 2012 went into biotech and another $16 \%$ into medical technology, venture capitalists are also the dominant investor type in life sciences.

Fig. 2 shows that $66 \%$ of the total CHF 2.7 billion investments into biotech and $57 \%$ of the total CHF 1.0 billion medtech investments were provided by venture capitalists. Other investors, conversely, play a more important role in other industries, such as investment companies in the field of ICT.

The intermediary function of venture capitalists is even more material if one considers the profile of investor demand. For instance, it is often argued that pension funds would be eligible investors for venture capital. This may be true from an economic perspective given the long time horizon of most of these institutions. However, due to the J-curve-like return profile and the high degree of uncertainty, making investments in start-ups is just not compatible with the requirements of Swiss pension funds in terms of risk and return profile against the background of current regulation and the time structure of retirement liabilities.

As for the regional pattern of venture capital flows, we observe that over the past decade, three main life sciences clusters in

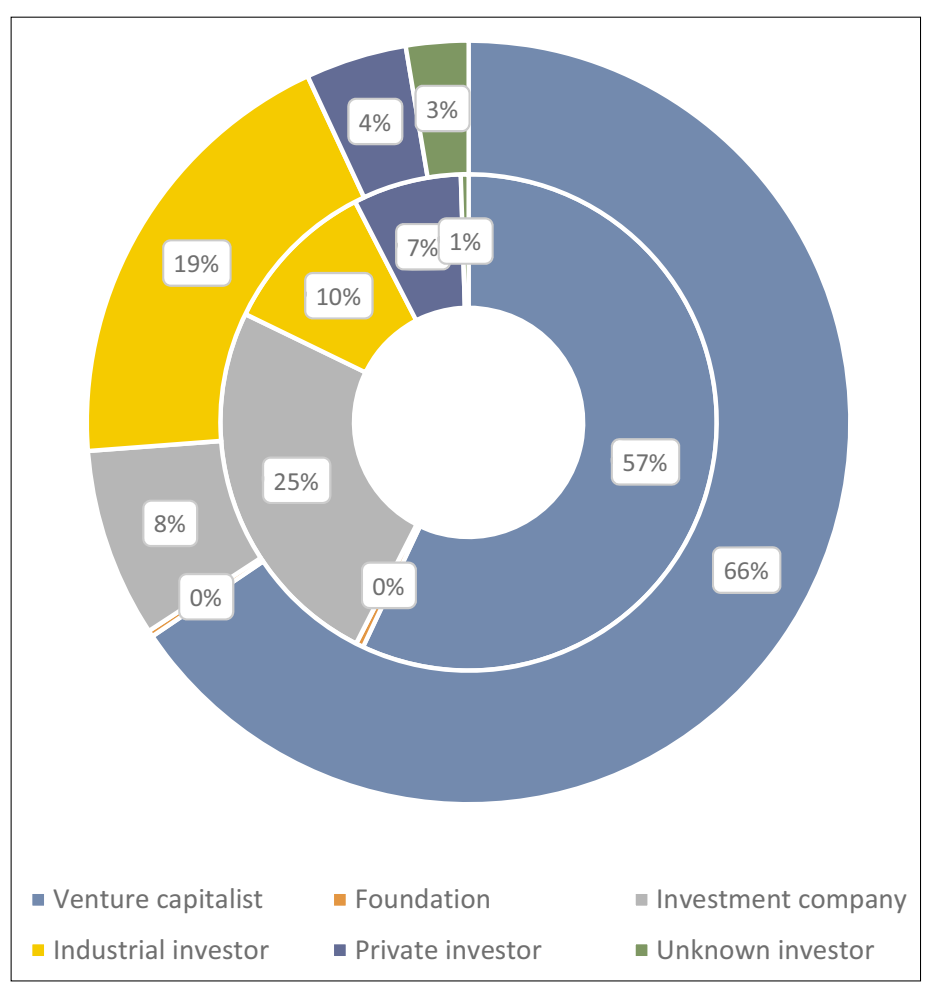

Fig. 2. Investor types in biotech (outer ring) and medtech (inner ring) measured by investment volume between 1999 and 2012 (source: Swiss Venture Capital Database, University of Basel).

Switzerland have emerged. For instance, $28 \%$ of all biotech start-up companies in Switzerland and $12 \%$ of all companies in medtech and diagnostics registered in the Swiss Start-up Monitor are located in the Basel area. While such hubs have already existed in Basel and the Arc Lémanique, the hub in Zurich is relatively new but features a fast growth. In these clusters, an above average proportion of venture capital gets allocated to life sciences. For example, in the Basel area, the percentage has been up to $80-90 \%$ in some years. The economics of life sciences clusters is based on the observation that proximity to the pharmaceutical industry as well as to universities and other academic institutions is perceived to be overly beneficial for firms in such a research intensive sector, which also exhibits a high number of university spin-offs.

\section{Challenges for Venture Capital Investments in Life Sciences}

Despite some differences in the venture capital flow patterns between biotechnology and medical technology, both life sciences subsectors face severe challenges. Three aspects are predominant, namely a) the availability of venture capital for innovative and promising start-ups both in the early and the expansion stage, b) how to manage the investment given the specific risk-return trade-off of life sciences investments, and c) which business models to choose for the companies active in these industries.
For the entrepreneurs, a fundamental problem exists in the observed cyclicality of investment flows. As could be seen during the financial crisis of 2008, not only the willingness of investors to make capital commitments has suffered. In addition, the constricted investment volume featured a shift from early to expansion financing. Both effects have led to a scarcity of venture capital for the early stage. Apart from some corporate investors, very few others have remained during that time - a setting which is clearly inefficient and costly for the industry. This point is further aggravated by the fact that very few firms in biotechnology are able to finance their R\&D expenses through self-generated cash flows. Hence, they are heavily exposed to external money flows.

Second, the industry exhibits a very specific risk-return profile. Investment risks for the research and development years until compounds can get approved are enormous. On average, the price tag per compound is at CHF 1 to 2 billion nowadays, while the success rates are extremely low. This also explains the ambiguous record regarding the return history and the high sensitivity of valuations towards changes in the market and the basic conditions. Because of this elevated risk profile, the sector exhibits a relatively high sensitivity towards changes in the overall stock market valuation. For instance, from 2007 to 2011, the segment of listed life sciences firms in the Swiss stock market has seen a more pronounced decline than the overall market. However, since the dip in 2011, life sciences have made up for most of the 
downturn showing above market returns. Both has a lot to do with the fact that returns from investments in life sciences, particularly in biotech, are not generated through cash flows from normal business activity, but either through licensing deals or the sale of the entire company. Hence, potential cash flows or proceeds are heavily back-loaded, requiring both a long investment horizon and the capability to bear losses; i.e. the readiness to accept that maybe just one out of twenty investments will ultimately turn out well. But, as mentioned, the risk is not just the investor's in selecting the wrong companies, it is very much also the other way round.

Finally, a permanent question for life sciences companies is which business models they should optimally pursue. Due to patent expiry of some of their blockbusters, big pharma is in need of new products based on top biotech research and on partnering solutions with biotech firms.
However, it is a challenge for both sides to find the right partner, as already collaborations, let alone takeovers, create substantial sunk costs. Typical ways of partnering include joint projects, in-licensing, the buildup of strategic shareholdings, and the full acquisition. Therefore, the difficulty of the industry is in choosing a suitable strategic partner, in arranging the appropriate sequence of collaboration steps, in mutually building the necessary trust, as well as in finding the right balance between risk sharing and maintaining as much flexibility as possible.

\section{Conclusions}

There are no easy solutions at hand. Clearly, a more efficient channeling of venture capital into the industry would be desirable. In particular, what is needed is a smoothing of both capital availability and investment returns combined with a professional investment management. Further, Switzerland should care for attractive basic conditions in order not to interfere with an efficient capital allocation. Only this can support technology leadership in this field, which is crucial for the country's future prosperity. And finally, it is also the industry's task to keep building an internationally competitive and visible high-technology cluster in Switzerland that is able to attract talents and investors from all over the world.

Received: September 9, 2014

66 Life science ventures are important to the pharmaceutical sector and a vital element for the industry to remain innovative. Such ventures in Switzerland are able to draw on a strong academic and corporate talent base, a stable legal and regulatory environment, and increasingly sophisticated investors. With these advantages, it is no surprise that Switzerland is among the most attractive locations for new life science ventures. Novartis remains an active investor in Swiss start-ups through our venture fund, and also through licensing and acquisitions.

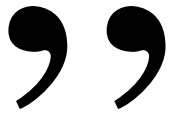

